\title{
O CASAMENTO PRECOCE NO BRASIL ENQUANTO VIOLAÇÃO DOS DIREITOS HUMANOS
}

\author{
EARLY MARRIAGE IN BRAZIL AS A VIOLATION OF HUMAN RIGHTS
}

Ana Clara de Moraes Bezerra*

\begin{abstract}
Resumo:
O presente artigo se propõe a analisar a realidade do casamento precoce no Brasil, enquanto grave violação dos direitos humanos, buscando suscitar o debate quanto à gravidade da situação brasileira e a busca por soluções possíveis. $\mathrm{O}$ casamento infantil constitui violação dos direitos humanos e, principalmente, das meninas. O Brasil é o quarto país no mundo em números absolutos de casamento precoce, sendo o país com os piores índices da América Latina. Entretanto, não há debates oficiais sobre o assunto, sendo que a questão não faz parte das agendas de governo, perpetuando, assim, a desigualdade de gênero e o ciclo da pobreza.

Palavras-chave: Casamento Precoce. Casamento Infantil. Direito Internacional. Direitos Humanos. Direito das Mulheres.
\end{abstract}

\begin{abstract}
:
The present essay proposes to analyze the reality of early marriage in Brazil, as a serious violation of human rights, seeking to elicit the debate about the seriousness of the Brazilian situation and the search for possible solutions. Child marriage is a violation of human rights, and especially of girls' rights. Brazil is the fourth country in the world in absolute numbers of precocious marriage, being the country with the worst rates in Latin America. However, there are no official debates on the subject, since the issue is not part of the government agendas, thus perpetuating gender inequality and the cycle of poverty.
\end{abstract}

Keywords: Early marriage. Child Marriage. International Law. Human Rights. Women's Rights.

\section{Introdução}

O casamento infantil constitui violação dos direitos humanos, sendo reconhecido como tal pela Organização das Nações Unidas (ONU) desde, pelo menos, 1962, com a Convenção sobre o Consentimento ao Casamento, a Idade Mínima para Casamento e Registro de Casamentos. Em 1979, a Convenção sobre a Eliminação de Todas as Formas de Discriminação contra as Mulheres (1979) estabelece em seu art. 16, II:

\footnotetext{
* Advogada. Bacharela em Direito pela Universidade de São Paulo. E-mail: anaclara.moraesbezerra@gmail. com. 
2. Os esponsais e o casamento de uma criança não terão efeito legal e todas as medidas necessárias, inclusive as de caráter legislativo, serão adotadas para estabelecer uma idade mínima para o casamento e para tornar obrigatória a inscrição de casamento em registro oficial. ${ }^{1}$

Ainda, o direito ao consentimento "livre e completo" para o casamento é reconhecido na Declaração Universal dos Direitos Humanos, ${ }^{1}$ que diz que o consentimento não pode ser "livre e completo" quando uma das partes envolvidas não é suficientemente madura para tomar uma decisão informada sobre um compromisso de tal magnitude; E, embora não seja mencionado diretamente na Convenção sobre os Direitos da Criança, o casamento infantil está vinculado a outros direitos - como o direito à liberdade de expressão, o direito à proteção de todas as formas de abuso e o direito de ser protegido de práticas tradicionais nocivas.

Neste contexto, fica claro o recorte de gênero, visto que, no Brasil, a maioria dos afetados por tal prática é do sexo feminino. Entretanto, apesar dos números alarmantes, muito pouco - ou quase nada - é feito para combater o casamento infantil.

Em verdade, o assunto sequer é debatido, por uma série de razões. Seja pela cultura conservadora que acha preferível uma garota se casar antes dos 15 anos de idade a exercer seu direito a dignidade sexual estando solteira, da mesma maneira que estabelece padrões retrógrados de masculinidade, levando homens a buscar maior controle sobre seus relacionamentos como forma de autoafirmação e, consequentemente, buscando parceiras cada vez mais jovens como forma de estabelecer seu domínio com maior facilidade. E, devido às diferenças entre a realidade brasileira e os arranjos ritualísticos do mundo árabe e de algumas regiões da África, que impedem o reconhecimento da situação verdadeiramente epidêmica do casamento precoce no Brasil, percebe-se uma resistência em admitir a gravidade da situação brasileira.

O combate ao casamento precoce é fundamental tanto para proteger os direitos básicos das meninas, quanto para possibilitar que seja atingida uma série de objetivos de desenvolvimento, incluindo os Objetivos de Desenvolvimento do Milênio (ODM) da ONU.

Assim, este artigo pretende conscientizar sobre a possibilidade de erradicação do casamento infantil e a necessidade de início imediato das medidas necessárias. Isso porque trabalhar o tema de casamentos nas faixas etárias mais vulneráveis é essencial

1 Art. 16. 1. A partir da idade núbil, o homem e a mulher têm o direito de casar e de constituir família, sem restrição alguma de raça, nacionalidade ou religião. Durante o casamento e na altura da sua dissolução, ambos têm direitos iguais. 2. O casamento não pode ser celebrado sem o livre e pleno consentimento dos futuros esposos. 3. A família é o elemento natural e fundamental da sociedade e tem direito à proteção desta e do Estado. 
para a realização dos direitos das crianças e adolescentes e para alcançar uma gama de objetivos relacionados ao desenvolvimento.

Ademais, não se pode ignorar que o Brasil assumiu diversos compromissos perante a comunidade internacional, a saber: a Convenção sobre o Consentimento ao Casamento, a Idade Mínima para Casamento e Registro de Casamentos (1962, promulgada pelo Decreto n. 66.605/1970), o Tratado de Eliminação de toda forma de discriminação contra a Mulher (1979, ratificado pelo Brasil em $1^{\circ}$ de fevereiro de 1984) e o Tratado dos Direitos da Criança (assinada e ratificada pelo Brasil em 1990) sendo que, até o presente momento, tem se omitido no cumprimento de suas obrigações internacionais, cabendo aqui a ressalva de que o termo "casamento", no que tange à realidade brasileira, se refere tanto às uniões formais quanto informais.

2. O casamento infantil enquanto violação dos Direitos Humanos

"Violência contra mulheres", segundo a Organização das Nações Unidas (ONU), é "qualquer ato de violência baseado no gênero do qual resulte, ou possa resultar, danos ou sofrimento físico, sexual ou psicológico para mulheres, incluindo a ameaça de tais atos, coerção ou privação arbitrária da liberdade, que ocorra, seja na vida pública ou na vida privada". Assim, dentre as diversas violações baseadas em gênero, pôde-se destacar o aborto em função do gênero; o aumento da mortalidade infantil feminina, abuso infantil, mutilação genital feminina, tráfico infantil e, em especial, o casamento infantil. (SAKHONCHIK; RECAVARREN; TAVARES, [2017], p. 1).

Embora a definição de casamento precoce ou infantil dada pela Convenção das Nações Unidas sobre os Direitos da Criança (CRC) seja de uma união envolvendo pelo menos um cônjuge abaixo dos 18 anos, as meninas são afetadas com muito mais intensidade do que os meninos, por uma série de fatores históricos, sociais e culturais. $\mathrm{O}$ recorte de gênero fica claro, de modo que se pôde inferir que, mais do que uma violação aos direitos humanos, o casamento precoce constitui uma violação aos direitos da mulher.

Ao restringir a liberdade e direito à educação, o casamento precoce gera desdobramentos que se estendem até a economia local, uma vez que a falta de estudos reduz significativamente a capacidade de tomada de decisões e obtenção de renda, de acordo com a declaração assinada por diversos grupos de especialistas em direitos humanos da ONU, na ocasião do primeiro Dia Internacional das Meninas, 11 de outubro de 2012, o que representa obstáculo tanto à ascensão social quanto ao empoderamento feminino em si. Portanto, o casamento precoce é considerado análogo à escravidão, por causar servidão doméstica, escravidão sexual e violações do direito à saúde, à educação, à não discriminação e à liberdade contra a violência física, psicológica e sexual. 
De acordo com o relatório Fechando a brecha: melhorando as leis de proteção à mulher contra a violência, realizado pelo segmento Mulheres, Empresas e o Direito do Grupo Banco Mundial, a violência doméstica, em suas mais variadas formas, inibe o empoderamento econômico da mulher, ao limitar sua capacidade de ação e tomada de decisões, preservando desta maneira a desigualdade de gênero. Uma garota que se casa antes dos 18 anos tem menos oportunidade de decidir sobre seu futuro, sendo forçada a aceitar uma posição subalterna, psicológica e economicamente, de modo a perpetuar o ciclo de pobreza e violência.

Ainda, não se pode ignorar questões relevantes relacionadas ao casamento precoce, como gravidez na adolescência, uma vez que diversos estudos realizados apontam para uma maior incidência de gravidez precoce e risco de morte em jovens casadas, e violência doméstica, pelo fato de casamentos na infância e na adolescência estarem inseridos em um contexto social que normaliza a violência de gênero ao reforçar padrões de comportamento que objetificam a mulher e a colocam em uma posição de inferioridade e submissão ao homem, como constatou a pesquisa "Ela vai no meu barco", realizada pelo Instituto Promundo.

A referida pesquisa também constatou que os direitos sexuais e reprodutivos das meninas expostas ao casamento precoce são majoritariamente ignorados, uma vez que o casamento é entendido como uma melhor alternativa ao desenvolvimento de uma vida sexual com mais de um parceiro e a educação formal é percebida como pouco atrativa ou fora de alcance.

Também se deve levar em conta que normas de gênero desiguais são reforçadas pela religião, mídia e pelas comunidades nas quais as meninas vivem, de modo que a principal função de um marido é entendida como a de provedor - já que as meninas não têm idade nem estudos o suficiente para se sustentarem sozinhas - o que favorece a escolha por homens mais velhos, mesmo que eles também enfrentem poucas oportunidades, ao mesmo tempo em que os homens desejam se casar com meninas mais jovens, consideradas mais atraentes e de mais fácil controle do que as mulheres adultas, adquirindo, assim, poder decisório desproporcional em decisões maritais.

No que tange a questão dos direitos humanos no âmbito internacional, observando a historicidade destes, destacando-se a concepção contemporânea de direitos humanos, introduzida pela Declaração Universal de 1948 e reiterada pela Declaração de Direitos Humanos de Viena de 1993. Neste cenário de esforço de reconstrução dos direitos humanos, foi a Declaração de Direitos Humanos de Viena de 1993 que, de forma explícita, estabeleceu, em seu parágrafo 18, que os direitos humanos das mulheres e das meninas são parte inalienável, integral e indivisível dos direitos humanos universais. Esta concepção foi reiterada pela Plataforma de Ação de Pequim, de 1995 (PIOVESAN, 2012, p. 75-76). 
Desse modo, a Declaração de Viena foi de vital importância para a construção de um contexto em que as mulheres passam a ser vistas nas especificidades e peculiaridades de sua condição social, e o reconhecimento destas peculiaridades implica o direito ao reconhecimento de identidades próprias, propiciando a incorporação da perspectiva de gênero, originando, assim, um novo conceito e entendimento dos direitos humanos a partir da relação entre os gêneros, como um tema transversal. (PIOVESAN, 2012, p. 75-76).

Quando da observação dos direitos humanos no âmbito internacional, percebe-se que, no que se refere à proteção dos direitos da mulher, os últimos trinta anos foram pautados por, basicamente, três vertentes: a discriminação contra a mulher; a violência contra a mulher; e os direitos sexuais e reprodutivos (PIOVESAN, 2012, p. 75-76), vertentes estas que, ainda que de forma indireta, incidem todas no tema abordado na presente pesquisa.

Tendo tais fatos em vista e estando o casamento precoce tão arraigado em questões sociais e culturais, faz-se necessária uma análise das raízes do formato de casamento que desencadeia essas questões, bem como sua função social.

\subsection{Breve escorço histórico}

\subsubsection{Do casamento}

O economista e sociólogo estadunidense Thorstein Veblen, em sua notória obra A teoria da classe ociosa: um estudo econômico das instituições (1924), estabelece a origem da propriedade na "propriedade que têm os homens capazes sobre as mulheres", ou seja, nos estágios mais primitivos, a mulher em nada se distinguia dos demais espólios de guerra, basicamente um troféu, tendo status de escrava e devendo total obediência a seu marido e senhor. $\mathrm{O}$ autor afirma ainda que:

Nos estágios mais baixos do barbarismo, a propriedade de mulheres começa aparentemente com a apropriação de mulheres cativas. (...). O costume de tomar violentamente as mulheres do inimigo, como troféus, resultou numa forma de casamento-propriedade, com a formação de uma estrutura familiar sob chefia de um homem. Estendeu-se depois a escravidão a outros cativos e dependentes, além de mulheres, desenvolvendo-se afinal o casamento-propriedade a outras mulheres além das tomadas ao inimigo. A consequência da emulação, nas circunstâncias da vida predatória, foi, portanto, de um lado uma forma de casamento, fundada na coerção, e de outro o costume da propriedade.

Desse modo, pode-se perceber que, desde as origens, o casamento teve como base uma relação de poder desigual entre homem e mulher, pautado pela dominação 
do gênero feminino. Inicialmente, por se tratar de um espólio de guerra, a mulher não tinha poder de agência dentro da própria casa, muitas vezes sequer falando o mesmo idioma que o marido. Esse modelo de casamento-propriedade, pautado pela coerção, acabou sendo exportado para relacionamentos com mulheres livres, sendo toda a estrutura familiar construída sob o controle masculino.

Assim, fica evidente a influência de tal modelo nos estereótipos de relacionamentos tradicionais, em que o homem é visto como o chefe da casa e da família, provedor e responsável pela tomada de decisões, enquanto à mulher cabe apenas a administração do lar e cuidados com os filhos, devendo obediência e submissão ao marido, sendo este mais do que seu papel social, verdadeira vocação biológica.

Também é notória a relação entre este modelo primitivo de casamento e a desigualdade de gênero, em que o homem é visto como capaz e independente, enquanto a mulher, quase um cidadão de segunda classe, apenas pode encontrar realização dentro do lar, constituindo família. Convém ressaltar que, embora tal visão possa ser considerada retrógrada, ainda encontra bastante respaldo na atualidade, com o advento da onda conservadora que tem se manifestado no país. É muito defendida ainda a ideia de que a mulher nasceu para se casar e cuidar da casa, por influência religiosa/pseudocientífica ou não, e aquelas que fogem desse padrão acabam sendo condenadas pela opinião pública, de modo geral.

Além desta breve análise da origem remota do conceito de casamento, outro aspecto bastante relevante para entender as raízes do casamento precoce é o histórico do processo de escolha do cônjuge, em conjunto com a evolução da idade núbil no Brasil.

\subsubsection{Da escolha do cônjuge e da idade núbil no Brasil}

O processo de escolha do cônjuge obedece a um complexo sistema de regras sociais, em todas as sociedades humanas, sejam tribais, civilizadas, rurais, urbanas, tradicionais ou modernas, como bem explica a professora Maria Stella Ferreira Levy em seu artigo A escolha do cônjuge, publicado na Revista Brasileira de Estudos de População, v. 26, n. 1, jan./jun. 2009.

No período colonial brasileiro, principalmente dentro das classes abastadas, questões de foro íntimo como amor ou atração física não possuíam nenhuma relevância para a escolha do cônjuge, sendo esta pautada quase que exclusivamente por razões pessoais do chefe da família, não cabendo à mulher qualquer participação na tomada de decisões nem poder de agência sobre a própria vida. Seu papel, assim, era completamente passivo, deixando clara a assimetria de gênero nas relações (LEVY, 2009, p. 119).

Quanto à questão da idade núbil, os casamentos com diferença de idade eram bastante comuns no período colonial, com o homem tradicionalmente mais velho. 
Casamentos entre mulheres mais velhas e homens mais jovens eram raros e, de uma maneira geral, mal vistos, havendo até casos em que a idade da mulher era adulterada nos registros para mascarar tal situação (LEVY, 2009, p. 125).

No que tange à questão da idade núbil, não havia idade mínima legal para casamento no Brasil e em Portugal, tendo como idade mínima presumida 12 anos para as meninas e 14 para os meninos, seguindo a tradição dos direitos romano e canônico, já que tais idades marcavam a puberdade para os romanos e concediam capacidade física e moral para casar no direito canônico (LEVY, 2009, p. 120).

Havia, entretanto, situações em que a idade poderia ser legalmente suprida, com autorização dos pais, ou, pelo menos, do pai e suprimento de idade pelo juiz de órfãos, como, por exemplo, a sponsalia de futuro em Portugal, promessas de casamento a ser contraído por pessoas hábeis e desimpedidas, ou seja, maiores de sete anos de idade (LEVY, 2009, p. 120). Segundo Clóvis Bevilacqua (1896, p. 15-16 e 86, apud LEVY, 2009, p. 120), os esponsais seriam uma transformação da anterior compra de mulheres, e a "confirmação do compromisso futuro materialisava-se pela dação de arrhas ou pela simples troca de anneis".

Inglaterra, Espanha, Grécia, Turquia, Hungria católica e Argentina também adotavam as idades núbeis mínimas de 12 e 14 anos, enquanto a França, com o Código Napoleônico, adotou as idades de 15 e 18 anos, para meninas e meninos, respectivamente, com autorização dos pais (FEIGUIN, 1970, p. 74-75 apud LEVY, 2009, p. 124), mesma idade adotada por Alemanha, Romênia, Rússia e Hungria protestante. Como casos excepcionais, tem-se a Suíça, que estabelecia 14 e 20/21, e Estados Unidos, que adotavam 12 e 17/18 anos, também respectivamente (BEVILACQUA, 1896, p. 86 apud LEVY, 2009, p. 124).

Com o decorrer do tempo, a questão da puberdade foi perdendo espaço para questões de cunho social dentro do casamento, como maturidade e desenvolvimento intelectual, passando a entender-se que o casamento engloba muito mais do que apenas a capacidade biológica de gerar filhos, e sim a capacidade moral de criá-los apropriadamente. Nesse contexto, o consentimento dos nubentes passa a ganhar maior destaque, sobrepondose, inclusive, à vontade paterna (LEVY, 2009, p. 125).

Assim, pelo art. $7^{\circ}, \S 8^{\circ}$, do Decreto n. 181 de 24 de janeiro de 1890 , promulgado pelo governo provisório da República, são proibidos de se casarem as mulheres menores de 14 anos e os homens menores de 16 anos, limites esses que definem por lei o casamento válido (LEVY, 2009, p. 125) e bastante próximos dos limites estabelecidos pelo Código Civil de 2002, a saber: 16 anos com autorização dos responsáveis para ambos os sexos, ou a maioridade civil, 18 anos, com previsão de algumas exceções que serão tratadas com maior profundidade mais adiante. 
Esse breve percurso histórico traz à tona questões relevantes para a análise do casamento infantil, principalmente no que diz respeito aos fatores que originam o casamento precoce. $\mathrm{O}$ ideário machista, ainda tão presente, preserva a concepção de que a mulher tem como única função e vocação a administração da casa e os cuidados com os filhos, e incentiva a união de meninas com homens mais velhos por estes serem mais maduros e responsáveis - através daquela máxima de que "as meninas amadurecem mais cedo que os meninos" - influenciando, por fim, a questão do poder de agência, sendo, de uma forma ou de outra, a última palavra sempre pertencente ao homem.

Com essas questões em vista, procede-se a uma análise da situação mundial do casamento precoce.

\subsection{O casamento infantil no mundo}

É de vital importância que se esclareça, desde o início, que, diferentemente do que acredita o senso comum, o casamento precoce não é estritamente vinculado a nenhuma localidade ou religião específicos. Trata-se de um problema global.

De acordo com os números apresentados no Banco de Dados Global do UNICEF, 39\% das mulheres entre 20-24 anos se casaram antes dos 18 anos na África Subsaariana, 36\% na África Oriental e Austral, 18\% no Oriente Médio e Norte da África, 15\% no Leste da Ásia e Pacífico, 23\% na América Latina e Caribe e 11\% no centro e Leste Europeu e na Comunidade dos Estados Independentes, atingindo-se a porcentagem de $41 \%$ das mulheres entre 20-24 anos nos países menos desenvolvidos.

Anualmente, estima-se que quinze milhões de meninas se casam antes da maioridade, totalizando 700 milhões de garotas afetadas pelo casamento precoce no mundo. Se nada for feito, as projeções feitas indicam que cerca de 950 milhões de mulheres terão casado ainda na infância/adolescência até 2030.

Fica bastante clara, com os dados apresentados, a ligação quase intrínseca do casamento precoce com a pobreza. Com especial destaque para as famílias que vivem abaixo ou no limiar da linha da pobreza, este tipo de união representa um alívio econômico, já que os pais deixam de ter a obrigação de sustentar a menina casada, ou mesmo algum tipo de ganho financeiro ou material direto, como ajuda financeira ou água e mantimentos. Dessa forma, além de contar com a anuência dos pais, o casamento precoce é até estimulado (NOUR, 2009, p. 51-56).

Outro aspecto bastante relevante é o conservadorismo apresentado pelos grupos sociais nos quais as garotas estão inseridas, atrelado ou não a alguma denominação religiosa. Dentro deste nicho, o casamento é visto como uma forma de controlar a sexualidade da jovem, e, mais do que isso, como a única alternativa a uma vida desregrada, 
de promiscuidade ou prostituição. Nesses contextos, a virgindade, atrelada ao ideal de pureza, e o decoro sexual são significativamente valorizados.

Como consequência disso, os resultados da pesquisa Ela vai no meu barco, do Instituto Promundo, sugerem que a tendência é que essas meninas raramente tenham mais de uma experiência sexual ou de namoro que não leve ao casamento ou à gravidez. Ou elas se casam com o primeiro parceiro sexual, em decorrência ou não de uma gravidez não planejada, ou acabam seguindo este modelo repetidamente, casando-se diversas vezes.

Assim, o casamento é concebido como única alternativa dentro de uma dicotomia de mobilidade e sexualidade controlada versus hipersexualização das meninas (começando na puberdade e incentivada pela sexualização das meninas pela mídia, pela música e pelas normas sociais). (TAYLOR; LAURO; SEGUNDO; GREENE, 2015, p. 75).

Essa questão, entretanto, vai muito além de conservadorismo puro e simples, sendo agravada pela falta de segurança nos bairros ou povoados periféricos, educação pública de qualidade e oportunidades de emprego. O casamento passa a ser visto, então, como uma forma de segurança, alimentando a percepção das meninas de que seus maridos as salvaram de uma vida "ruim", o que as levam a suportar diversos tipos de abusos, físicos ou psicológicos, por medo de serem abandonadas e, não tendo como garantir o próprio sustento, acabarem envolvidas com o crime ou prostituição.

Por fim, no que se refere ao casamento precoce no âmbito internacional, é fundamental tratar da crise mundial de refugiados. Desencadeada pela guerra na Síria e outros conflitos armados, a questão dos refugiados tem levantado importantes debates em todo o mundo. Entretanto, uma consequência grave dos fluxos imigratórios tem ficado em segundo plano: o aumento drástico no casamento precoce (VAN ORANJE, 2015).

Antes do início dos conflitos, a Síria não possuía índices alarmantes de casamento precoce (13\% das meninas casadas aos 18 anos). Entretanto, nos campos de refugiados, os números parecem ter dobrado. Sob a alegação de proteger a filha e fazer o melhor possível para garantir sua segurança, muitos pais defendem a ideia de um casamento precoce, normalmente com homens mais velhos. (VAN ORANJE, 2015), como forma de garantir sua segurança ou estadia no país, forçando os governos destes países a enfrentar seriamente esta questão.

\section{O contexto brasileiro}

Os índices de casamento precoce no Brasil são bastante elevados. Estimase que 3 milhões de jovens de 20 a 24 anos tiveram o matrimônio formalizado antes da maioridade, $36 \%$ do total de mulheres casadas dessa faixa etária, sendo o maior da América Latina e o $4^{\circ}$ mais alto do mundo em valores absolutos. Importa ressaltar que não 
houve estimativa, por falta de dados, dos índices de casamento precoce em países como China e Arábia Saudita, o que não torna, de modo algum, a situação brasileira menos grave.

Tais dados foram estimados pela Pesquisa Nacional de Demografia e Saúde da Criança e da Mulher, do Ministério da Saúde, em 2006, e contextualizados globalmente pelo UNICEF e pela organização não governamental Promundo. ${ }^{2}$

Como já foi explanado no capítulo anterior, o casamento precoce tem um forte vínculo com a pobreza e a desigualdade social, mazelas que persistem como problemas latentes na sociedade brasileira, muito embora o combate à pobreza extrema (pessoas que vivem com menos de US\$ 1,25 por dia, segundo metodologia do Banco Mundial) e a redução da pobreza estejam presentes na pauta de vários governos.

Contudo, a pobreza afeta de maneira severa crianças e adolescentes com mais intensidade do que afeta os adultos, como se pode observar nas tabelas a seguir.

Total e percentual de população em situação de pobreza- $2015^{3}$

\begin{tabular}{|c|c|c|}
\hline Brasil e regiões & $\begin{array}{c}\text { População com renda } \\
\text { até 1/2 salário-mínimo }\end{array}$ & \% \\
\hline Total & 55.409 .890 & 27,0 \\
\hline Nordeste & 26.044 .917 & 46,0 \\
\hline Norte & 7.540 .523 & 43,0 \\
\hline Centro-Oeste & 2.735 .058 & 17,7 \\
\hline Sudeste & 15.067 .282 & 17,5 \\
\hline Sul & 4.022 .110 & 13,7 \\
\hline
\end{tabular}

2 "Brasil tem maior número de casamentos infantis da América Latina e o $4^{\circ}$ mais alto do mundo". Nações Unidas do Brasil (2017).

3 Fonte: IBGE, Pesquisa Nacional por Amostra de Domicílios (Pnad) apud CINTRA; BOBADILLA; GAUTO, 2017, p. 21. 
Total e percentual da população de zero a 14 anos de idade em situação de pobreza $-2015^{4}$

\begin{tabular}{|c|c|c|}
\hline Brasil e regiões & $\begin{array}{c}\text { População com renda } \\
\text { até 1/2 salário-mínimo }\end{array}$ & \% \\
\hline Total & 17.322 .983 & 40,2 \\
\hline Nordeste & 8.046 .951 & 60,6 \\
\hline Norte & 2.525 .711 & 54,0 \\
\hline Centro-Oeste & 954.726 & 28,4 \\
\hline Sudeste & 4.520 .695 & 27,8 \\
\hline Sul & 1.274 .900 & 23,1 \\
\hline
\end{tabular}

Como se pode observar, a pobreza afeta de maneiras bastante distintas adultos e crianças, de modo que a pobreza infantil, sendo um fenômeno multifacetado, demanda uma análise diferenciada, para que se criem políticas públicas que ofereçam condições de romper o ciclo de reprodução da pobreza.

Isso porque, devido à privação de condições adequadas de higiene, saúde e alimentação na fase de desenvolvimento, as crianças e jovens submetidos à pobreza e à pobreza extrema podem carregar sequelas físicas, de desenvolvimento e de aprendizado, o que limita sua capacidade de ascensão social. Desta maneira, os menores de idade afetados pela pobreza tendem a reproduzir o ciclo, não havendo muitas possibilidades de ascensão social (CEPAL, 2017, p. 35 apud CINTRA; BOBADILLA; GAUTO, 2017, p. 18).

Importa ressaltar que, como o combate à pobreza faz tradicionalmente parte das agendas de governo, foram obtidos importantes avanços nesta seara, em especial graças ao Programa Bolsa Família, o maior programa de transferência direta de renda com condicionalidades do Brasil, que beneficia milhões de famílias em situação de pobreza e pobreza extrema no país (CINTRA; BOBADILLA; GAUTO, 2017, p. 28).

O Programa pauta-se na promoção do alívio imediato da pobreza (transferência de renda), reforço ao exercício de direitos sociais básicos nas áreas de saúde e educação, por meio do cumprimento das condicionalidades, e coordenação de programas complementares, que têm por objetivo o desenvolvimento das famílias, para que os beneficiários do Bolsa Família consigam superar a situação de vulnerabilidade e pobreza. (MINISTÉRIO DO DESENVOLVIMENTO SOCIAL, [20-?] apud CINTRA; BOBADILLA; GAUTO, 2017, p. 28).

${ }_{4}$ Fonte: IBGE, Pesquisa Nacional por Amostra de Domicílios (Pnad) apud CINTRA; BOBADILLA; GAUTO, 2017, p. 24. 
Uma ressalva importante a ser feita é que, embora fortemente atrelado à pobreza, o casamento precoce não se limita aos estados com maior contingente populacional em situação de pobreza nem a rincões isolados em áreas remotas do país, como demonstra a tabela a seguir.

\section{Distribuição dos registros de casamento de menores de 19 anos de idade - sexo feminino - estados com pior desempenho - $2015^{5}$}

\begin{tabular}{|c|c|c|c|}
\hline Estados & $\begin{array}{c}\text { Menos de 15 } \\
\text { anos }\end{array}$ & $\mathbf{1 5}$ a 19 anos & $\begin{array}{c}\text { Total de casamentos } \\
\text { com meninas menores } \\
\text { de } \mathbf{1 9} \text { anos }\end{array}$ \\
\hline São Paulo & 8 & 25.553 & 25.561 \\
\hline Minas Gerais & 6 & 13.680 & 13.686 \\
\hline Paraná & 117 & 8.709 & 8.826 \\
\hline Ceará & 5 & 6.991 & 6.996 \\
\hline Bahia & 10 & 6.834 & 6.844 \\
\hline
\end{tabular}

Entretanto, o casamento precoce é um fenômeno complexo, não sendo a pobreza o único fator que o desencadeia. Como já foi apontado no capítulo anterior, a pesquisa Ela vai no meu barco indica três influências complementares ao casamento precoce: o papel da religião, a mídia, e a insegurança urbana. Cada um desses fatores molda padrões de comportamento que naturalizam e até incentivam o casamento infantil.

As crenças religiosas têm um papel significativo na medida em que limitam os direitos das meninas à mobilidade e dignidade sexual, sustentando o patriarcado e defendendo normas desiguais de gênero. Acrescenta-se a isso a hipersexualização das meninas, incentivada pela mídia, pela música e pelas normas sociais (TAYLOR; LAURO; SEGUNDO; GREENE, 2015, p. 75) já que, dentro de um universo limitado de possibilidades, a única escapatória possível a uma vida de promiscuidade é o casamento, sem meio termo.

A violência urbana, aliada a precariedade e vulnerabilidade das comunidades onde o casamento infantil tem maior prevalência, caracterizada por baixos níveis de escolaridade, infraestrutura deficiente, fraca presença do Estado e de aplicação de políticas públicas, também tem um papel relevante neste cenário, já que a insegurança urbana reforça a lógica de que as meninas precisam ter um parceiro para garantir sua segurança, para que não fiquem sozinhas (sozinhas de modo geral além de sozinhas na rua). (TAYLOR; LAURO; SEGUNDO; GREENE, 2015, p. 70).

\footnotetext{
Fonte: IBGE, Estatísticas do Registro Civil apud CINTRA; BOBADILLA; GAUTO, 2017, p. 102.
} 
Além desses fatores, a pesquisa Ela vai no meu barco também aponta a fragilidade das estruturas familiares como causa para o casamento precoce, ante a incapacidade das famílias de proporcionar oportunidades às crianças. De acordo com essa perspectiva, o enfraquecimento de tais estruturas leva meninas a buscar estabilidade e segurança no casamento, que surge como opção mais viável, mas também como um modo de fuga das condições insalubres a que são submetidas.

Importa ressaltar que, apesar das duras condições de vida e da educação formal de baixa qualidade disponibilizada pelo Estado, as meninas têm seus sonhos e aspirações profissionais, e almejam, se não a independência financeira, pelo menos contribuir com as finanças domésticas. Uma vez casadas, entretanto, elas percebem que suas opções, já restringidas pela falta de educação e de oportunidades de emprego, se tornam ainda mais escassas, quer seja pelo próprio marido ou por gravidez/filhos. (TAYLOR; LAURO; SEGUNDO; GREENE, 2015, p. 74).

\subsection{Do recorte de gênero}

Não se pode discutir o casamento precoce sem uma análise mais detalhada da desigualdade de gênero no Brasil e de sua influência no cenário atual. Isso porque não há como discutir o combate à violação dos direitos humanos contra as meninas sem discutir a questão da desigualdade de gênero e a necessidade de empoderamento feminino.

O último Relatório de Desenvolvimento Humano, publicado pelo Programa das Nações Unidas para o Desenvolvimento (PNUD), indica que as mulheres constituem um dos grupos sociais mais privados de dimensões básicas do desenvolvimento humano, como acesso à renda, oportunidades e condições adequadas de saneamento básico (PNUD, 2016 apud CINTRA; BOBADILLA; GAUTO, 2017, p. 89). Portanto, ainda que com expectativa de vida maior e um nível de escolaridade mais alto do que os homens, a desigualdade e a privação marcam e afetam a qualidade de vida de mulheres de forma significativa. (CINTRA; BOBADILLA; GAUTO, 2017, p. 89).

A desigualdade de gênero se inicia na infância, quando meninas e meninos recebem tratamento distinto. Na pesquisa Por Ser Menina no Brasil, realizada pela ONG Plan International Brasil em 2013, constatou-se que as meninas dedicam muito mais tempo às tarefas domésticas, pois as famílias entendem que esse aprendizado é fundamental para que elas aprendam seu "papel" enquanto mulher. (CINTRA; BOBADILLA; GAUTO, 2017, p. 91).

Embora pareça inofensivo ou bem-intencionado, na prática, isso significa que as meninas têm menos tempo para dedicar-se a suas atividades pessoais, estudos, lazer e desenvolvimento de suas potencialidades, e isso acaba por perpetuar estereótipos 
de gênero, tanto para meninas quanto para meninos, que tem imposto o exercício de uma masculinidade violenta. (CINTRA; BOBADILLA; GAUTO, 2017, p. 91).

$\mathrm{E}$, assim, a desigualdade de gênero que dá origem ao casamento infantil se perpetua no âmbito da relação do casal, sendo o controle sobre as meninas ainda mais intenso e rígido, ante o controle que o homem exerce sobre a sexualidade e mobilidade da menina. (TAYLOR; LAURO; GREENE, 2015, p. 75).

Até mesmo que a questão da educação é afetada pela desigualdade de gênero. $\mathrm{O}$ aprendizado, no que se relaciona às meninas, é associado ao casamento, como uma forma de "aprender a ser mulher". A educação, neste contexto, é mais associada ao casamento do que à escola, o que acaba justificando os casamentos e consolidando a dominação masculina.

Por fim, não se pode deixar de falar sobre a violência de gênero, definida da seguinte forma:

\begin{abstract}
A violência de gênero é um reflexo direto da ideologia patriarcal, que demarca explicitamente os papéis e as relações de poder entre homens e mulheres. Como subproduto do patriarcalismo, a cultura do machismo, disseminada muitas vezes de forma implícita ou sub-reptícia coloca a mulher como objeto de desejo e de propriedade do homem, o que termina legitimando e alimentando diversos tipos de violência, entre os quais o estupro. Isto se dá por dois caminhos: pela imputação da culpa pelo ato à própria vítima (ao mesmo tempo em que coloca o algoz como vítima); e pela reprodução da estrutura e simbolismo de gênero dentro do próprio Sistema de Justiça Criminal (SJC), que vitimiza duplamente a mulher (IPEA, 2014 apud CINTRA; BOBADILLA; GAUTO, 2017, p. 90).
\end{abstract}

A pesquisa Ela vai no meu barco aponta que experiência de violência dentro do casamento infantil são comuns, partindo do controle exercido sobre a mobilidade e sexualidade das meninas até violência física, sendo a injustiça marital uma fonte de conflitos recorrentes. As meninas que se casam acabam expostas à Violência contra a Parceira Íntima (VPI) em grande parte porque o contexto em que se dão esses casamentos normaliza a violência contra a mulher, com a ideia de que a mulher é um objeto sexual e pertence ao homem. (TAYLOR; LAURO; SEGUNDO; GREENE, 2015, p. 87).

\title{
3.2. A legislação brasileira
}

A seriedade da situação brasileira deve-se, em parte, a legislação em desacordo com os compromissos assumidos perante a comunidade internacional e com os debates sobre o casamento precoce. 
$\mathrm{O}$ art. 1.517 do Código Civil de 2002 prevê que, antes da maioridade civil, aos 18 anos, os jovens de 16 anos podem se casar com autorização paterna. Como a Convenção das Nações Unidas sobre os Direitos da Criança (CRC) ${ }^{6}$ define criança como todo aquele com menos de 18 anos de idade, pode-se inferir que, na prática, o casamento precoce é legalizado.

A previsão do art. 1.519 do referido Diploma Legal também é preocupante, pois estabelece que a denegação de consentimento por parte dos pais ou responsáveis legais pode ser suprimida pelo juiz, quando injusta. Ora, como a negativa de consentimento de casamento de menores de idade pode ser injusta? Qual é o critério para avaliar se a decisão dos pais é justa ou não? O texto deste artigo traz uma subjetividade perigosa, de modo que, no fim, a decisão sobre o casamento precoce depende da opinião pessoal do magistrado.

Contudo, a previsão mais grave e mais em desacordo com os debates internacionais é a que trazia o art. 1.520. Dispunha o referido artigo que

1.520. Excepcionalmente, será permitido o casamento de quem ainda não alcançou a idade núbil (art. 1.517), para evitar imposição ou cumprimento de pena criminal $^{7}$ ou em caso de gravidez.

Impera ressaltar que tal artigo não está mais em vigor. A Lei n. 13.811 de 2019 alterou a redação do referido artigo, que passou a ser:

Art. 1.520. Não será permitido, em qualquer caso, o casamento de quem não atingiu a idade núbil, observado o disposto no art. 1.517 deste Código.

Ainda que se leve em conta o fato de que o casamento precoce no Brasil, como um todo, é marcado pela informalidade e consenso, não deixa de ser uma postura institucional conservadora a manutenção da legislação tal como se encontra, naturalizando o casamento de menores de idade, como se não fosse uma questão social complexa, grave e - acima de tudo - violação dos direitos humanos.

Como se pode perceber, a legislação brasileira é ainda bastante conservadora e encontra-se quase que completamente alheia aos debates internacionais sobre o assunto, sendo os avanços legislativos conquistados em 2019 ainda pequenos, incapazes de enfrentar seriamente a questão do casamento infantil, mesmo no que se refere aos

\footnotetext{
$6 \quad$ Assinada e ratificada pelo Brasil em 1990.

7 A Lei n. 11.106/2005 revogou expressamente os incisos VII e VIII do art. 107 do Código Penal, que previam a extinção da punibilidade pelo casamento com a vítima, de modo que o previsto na primeira parte do art. 1.520 do CC já não mais se aplicava.
} 
compromissos internacionais referentes a tratados assinados e ratificados há quase trinta anos.

Ademais, não se vislumbram propostas ou mesmo debates legislativos sérios sobre o assunto atualmente no país. Pelo contrário, o Estado brasileiro, de uma maneira geral, mostra-se bastante omisso à situação do casamento precoce no país.

\section{Possíveis intervenções}

Uma vez exposta a gravidade da situação brasileira no que se refere ao casamento infantil, deve-se agora analisar as diversas proposições existentes para a erradicação do casamento precoce, uma vez que constitui um dos objetivos do milênio, no que se refere à igualdade de gênero.

De maneira geral, as ações visando a erradicação do casamento infantil podem ser divididas em três vertentes básicas (TAYLOR; LAURO; SEGUNDO; GREENE, 2015, p. 117):

a) Fortalecimento da legislação e de serviços de proteção que garantam os direitos da criança e do adolescente;

b) Participação dos setores de educação e saúde; e

c) Transformar as normas sociais que sustentam o casamento na infância e adolescência.

O foco deste artigo, como já ressaltado anteriormente, é, justamente, abordar o casamento infantil no Brasil sob a óptica do direito internacional dos direitos humanos e, no caso, demonstrar que o Brasil já assumiu diversos compromissos internacionais que, direta ou indiretamente, implicariam em mudança da legislação interna.

Como ensina o professor Cançado Trindade, os tratados de direitos humanos das Nações Unidas são a base do sistema universal de proteção dos direitos humanos, devendo ser abordados não de forma isolada ou compartimentalizada, mas relacionados uns aos outros. Entretanto, ainda não se atingiu a ratificação universal nem sequer das seis Convenções Centrais - os dois Pactos de Direitos Humanos, as Convenções sobre a Eliminação de Todas as Formas de Discriminação - Racial e contra a Mulher, - a Convenção contra a Tortura, e a Convenção sobre os Direitos da Criança - possuindo tais convenções diversas reservas que não são compatíveis com o objeto e propósito dos tratados. (TRINDADE, 1997, p. 169).

Mais do que isso, percebe-se um descaso com os direitos econômicos, sociais e culturais, reflexo da desigualdade social. O princípio da não discriminação deve ser aplicado também ao aspecto econômico, de modo a combater a perpetuação da pobreza, 
que, no fim, é causa primeira de tantas mazelas que afetam este país. (TRINDADE, 1997, p. 170).

Entretanto, o foco principal deste tópico é justamente a necessária integração entre as iniciativas no plano internacional e o aperfeiçoamento das medidas nacionais de implementação, pois é aqui que os direitos humanos são efetivamente garantidos. De nada adianta a ratificação de todos os tratados existentes se não há qualquer proposta, qualquer esforço na efetivação das recomendações internacionais. (TRINDADE, 1997, p. 175).

É sempre importante ressaltar que a responsabilidade primária pela observância dos direitos humanos é dos Estados, responsabilidade esta atribuída pelos tratados de direitos humanos. Ao ratificarem estes tratados, os Estados Partes contraem a obrigação geral de adequar seu ordenamento jurídico interno ao compromisso internacional assumido, ou seja, deve ocorrer a subsunção do ordenamento jurídico interno em prol do tratado ratificado. (TRINDADE, 1997, p. 175).

Na proteção dos direitos humanos, direito internacional e o direito interno devem manter constante interação. Enquanto a proteção internacional requer medidas nacionais de implementação dos tratados de direitos humanos, o fortalecimento das instituições nacionais se dá com a vigência plena dos direitos humanos e do Estado de Direito. (TRINDADE, 1997, p. 175).

E é justamente neste aspecto que o Brasil vem falhando. Os tratados que dizem respeito à igualdade de gênero e direito das crianças foram devidamente assinados, ratificados e promulgados. Entretanto, o Código Civil continua prevendo exceção de idade núbil, diametralmente oposta aos princípios que regem e levaram a confecção de tais tratados.

Dada a gravidade da situação, o Brasil não pode mais se omitir ao cumprimento das obrigações internacionais que deliberadamente assumiu, já que não é dado a nenhum país alegar exceção de direito interno para se escusar do cumprimento das obrigações internacionais.

A isso se acrescente a posição adotada pelo STF quando do julgamento do RE n. 466.343-SP, Relator Cezar Peluso, em que, por maioria de votos, foi acatada a posição do Min. Gilmar Mendes, sustentando que os tratados internacionais de Direitos Humanos não aprovados pelo Congresso Nacional no rito especial do art. $5^{\circ}, \S 3^{\circ}$ da $\mathrm{CF} / 88$ têm natureza supralegal, ou seja, não recebem status constitucional, mas encontram-se acima de toda e qualquer lei. (CARVALHO RAMOS, 2009, p. 244).

Portanto, a primeira e principal intervenção defendida nesta tese é a alteração do Código Civil, para que a idade núbil seja fixada em 18 anos, tal qual a maioridade civil, sem qualquer exceção à idade núbil mínima.

Quanto às demais frentes de combate ao casamento precoce, percebe-se que a implementação dos direitos humanos das mulheres está, em grande parte, condicionada 
à dicotomia entre os espaços público e privado, que, em muitas sociedades, inclusive a nossa, confina a mulher ao espaço exclusivamente doméstico. (PIOVESAN, 2012, p. 7677).

Neste sentido, uma abordagem que envolva apenas as meninas não seria efetiva, sendo necessária a mobilização das famílias, e, principalmente, dos homens e meninos contra o casamento infantil. É necessário que haja conscientização sobre a desigualdade de gênero, importante fator na perpetuação dos estereótipos de gênero e, por consequência, na desvalorização da mulher.

Uma reforma no sistema educacional também se faz necessária, pois os resultados das pesquisas que lastrearam esta tese demonstram que o sistema educacional atual está falido, e esse método one size fits all é incapaz de despertar o interesse dos jovens e realmente criar oportunidades de desenvolvimento e ascensão social.

Também é importante que haja conscientização sobre os riscos do casamento precoce, visto que, dentro das especificidades do modelo brasileiro, acaba por vezes sem a devida notoriedade, embora os danos causados às jovens ao assumir tal tipo de compromisso, numa idade em que não possuem condições físicas nem psicológicas para tanto, sejam tão graves quanto as hipóteses tradicionalmente associadas ao casamento precoce, das uniões de cunho ritualístico associadas ao islamismo.

Ademais, é importante a criação de uma rede de apoio para as jovens já casadas, fomentando sua educação e dando o suporte necessário para que elas possam se desenvolver plenamente. No caso das vítimas de violência doméstica ou de menores de idade casadas com homens muito mais velhos, deve haver uma intervenção também, de modo a garantir os direitos básicos das vítimas. Para que o Brasil atinja os ODM até o ano de 2030 e para a consecução dos direitos humanos em sua plenitude, nenhuma garota pode ficar para trás.

\subsection{Soluções em Direito Comparado}

Encerra-se o presente artigo com alguns exemplos de países que têm se empenhado no combate ao casamento precoce, mais especificamente, em bons exemplos de práticas legislativas que poderiam - e deveriam - inspirar o legislador brasileiro.

O Camboja, em seu Código Civil, permite que o cônjuge, seus pais/ responsáveis legais ou um promotor público anulem um casamento quando um dos cônjuges tem idade abaixo da permitida por lei. Na Suíça, também há hipótese de anulação quando ao menos um dos cônjuges for menor; na Índia, a Lei de Proibição do Casamento Infantil permite que o tribunal emita uma ordem impedindo um casamento infantil e anule os casamentos já realizados. (SAKHONCHIK; RECAVARREN; TAVARES, 2017, p. 8). 
Ainda, quase metade das economias estudadas no relatório Fechando a Brecha prevê algum tipo de punição para aqueles que realizam, autorizam ou contraem um casamento em desrespeito à lei, normalmente multa ou prisão. Ainda, entre 2013 e 2015, Quênia, Luxemburgo, Nicarágua, Uruguai e Malawi aumentaram a idade de casamento para meninas. (SAKHONCHIK; RECAVARREN; TAVARES, 2017, p. 8).

\section{Conclusão}

O objetivo principal deste artigo é a conscientização para a gravidade da questão do casamento infantil no mundo, em especial no Brasil. Tal prática afeta milhares de jovens todos os anos, e muito pouco, ou quase nada, é feito para se solucionar isso. O casamento precoce traz graves consequências para as meninas, seus filhos e a sociedade como um todo.

A experiência e o debate internacionais nos mostram que existem soluções viáveis, existe um plano de ação de combate ao casamento precoce, mas é necessário que o Brasil saia da inércia em que se encontra. Pesquisas, debates e políticas públicas são medidas fundamentais e que se fazem urgentes.

A assinatura e ratificação são importantes, mas de nada adiantam se não houver um esforço no cumprimento das obrigações assumidas perante a comunidade internacional. É passada a hora de o país adequar a legislação ao conteúdo dos tratados que entendeu por bem assinar.

Mais do que isso, é preciso haver uma profunda alteração nas normas sociais, na cultura de exploração e subjugação da mulher. O problema do casamento infantil, antes de uma questão socioeconômica ou cultural, é uma questão de desigualdade de gênero.

Portanto, as questões de gênero devem ser debatidas, a desigualdade de gênero precisa ser combatida, assim como os estereótipos e a desvalorização do trabalho doméstico. Um país que se compromete com a defesa dos direitos humanos não pode mais coadunar com tal situação.

São Paulo, abril de 2019.

\section{Referências}

BRASIL. Decreto n. 4.377, de 13 de setembro de 2002. Promulga a Convenção sobre a Eliminação de Todas as Formas de Discriminação contra a Mulher, de 1979, e revoga o Decreto n. 89.460, de 20 de março de 1984. Portal do Planalto, Brasília, DF, set. 2002. Disponível em: http://www.planalto. gov.br/ccivil_03/decreto/2002/d4377.htm. Acesso em: 16 ago. 2017. 
BRASIL. Decreto n. 66.605, de 20 de maio de 1970. Promulga a Convenção sobre Consentimento para Casamento, 1962. Portal do Senado Federal, Brasília, DFD, maio 1970. Disponível em: http:// legis.senado.gov.br/legislacao/ListaTextoIntegral.action?id=95102. Acesso em: 16 ago. 2017.

BRASIL. Decreto n. 99.710, de 21 de novembro de 1990. Promulga a Convenção sobre os Direitos da Criança. Portal do Planalto, Brasília, DF, nov. 1990. Disponível em: http:/www.planalto.gov.br/ ccivil_03/decreto/1990-1994/d99710.htm. Acesso em: 14 abr. 2016.

CARVALHO RAMOS, André de. Supremo Tribunal Federal brasileiro e o controle de convencionalidade: levando a sério os tratados de direitos humanos. Revista da Faculdade de Direito da Universidade de São Paulo, São Paulo, v. 104, p. 241-286, jan./dez. 2009. Disponível em: http://www.revistas.usp.br/rfdusp/article/view/67857/70465. Acesso em: 25 abr. 2017.

CINTRA, João Pedro Sholl; BOBADILlA, Kassia Beatriz; GAUTO, Maitê. A criança e o adolescente nos ODS: marco zero dos principais indicadores brasileiros. ODS 1, 2, 3 e 5. São Paulo: Fundação Abrinq pelos Direitos da Criança e do Adolescente. Disponível em: https://issuu.com/ fundacaoabrinq/docs/publica___o_a_crian_a_e_o_adolesc. Acesso em: 14 set. 2017.

LEVY, Maria Stella Ferreira. A escolha do cônjuge. Revista Brasileira de Estudos de População, São Paulo, v. 26, n. 1, p. 117-133, jan./jun. 2009. Disponível em: http://www.scielo.br/pdf/rbepop/ v26n1/v26n1a09.pdf. Acesso em: 28 ago. 2017.

NAÇÕES UNIDAS. Brasil tem maior número de casamentos infantis da América Latina e o $4^{\circ}$ mais alto do mundo. [S. l.], 2017. Disponível em: https://nacoesunidas.org/brasil-tem-maior-numero-decasamentos-infantis-da-america-latina-e-o-4o-mais-alto-do-mundo/. Acesso em: 12 set. 2017.

NAÇÕES UNIDAS. Declaração Universal dos Direitos Humanos. Paris, 1948. Disponível em: http://www.ohchr.org/EN/UDHR/Documents/UDHR_Translations/por.pdf. Acesso em: 16 ago. 2017.

NOUR, Nawal M. Child marriage: a silent health and human rights issue. Reviews in Obstetrics \& Gynecology, Glastonbury, CT, v. 2, n. 1, p. 51-56, Winter 2009. Disponível em: http://medreviews. com/journal/reviews-in-obstetrics-gynecology/vol/2/no/1/child-marriage-silent-health-and-humanrights-issue. Acesso em: 27 maio 2016.

PIOVESAN, Flávia. A proteção internacional dos Direitos Humanos das mulheres. Revista da EMERJ, Rio de Janeiro, v. 15, n. 57, p. 70-89, jan./mar. 2012. Disponível em: http://www.emerj.tjrj. jus.br/revistaemerj_online/edicoes/revista57/revista57_70.pdf. Acesso em: 5 set. 2017.

REACH. Children on the move in Italy and Greece. June 2017. Disponível em: https://www.unicef. pt/media/1483/102-reach-criancas-em-movimento-italia-grecia.pdf.

SAKHONCHIK, Alena; RECAVARREN, Isabel Santagostino; TAVARES Paula. Fechando a brecha: melhorando as leis de proteção à mulher contra a violência. [2017]. Disponível em: http:// pubdocs.worldbank.org/en/200461519938665165/Topic-Note-Protecting-Women-from-ViolencePOR.pdf. Acesso em: 25 abr. 2017. 
TAYLOR, Alice Y.; LAURO, Giovanna; SEGUNDO, Marcio; GREENE, Margaret E. "Ela vai no meu barco": casamento na infância e adolescência no Brasil. Resultados de Pesquisa de Método Misto. Rio de Janeiro e Washington DC: Instituto Promundo \& Promundo-US, set. 2015. Disponível em: http://promundo.org.br/recursos/ela-vai-no-meu-barco-casamento-na-infancia-e-adolescenciano-brasil/. Acesso em: 14 abr. 2016.

TRINDADE, Antônio Augusto Cançado. Dilemas e desafios da Proteção Internacional dos Direitos Humanos no limiar do século XXI. Revista Brasileira de Política Internacional, Brasília, v. 40, n. 1, p. 167-177, jan./jun. 1997. Disponível em: http://www.scielo.br/scielo.php?script=sci_arttext\&p $\mathrm{id}=$ S0034-73291997000100007. Acesso em: 28 ago. 2017.

UNICEF. Child marriage. 2017. Disponível em: https://data.unicef.org/topic/child-protection/ child-marriage/. Acesso em: 8 ago. 2017.

VAN ORANJE, Mabel. Child marriage: a devastating effect of the refugee crisis. Oct. 2015. Disponível em: https://www.weforum.org/agenda/2015/10/child-marriage-a-devastating-effect-ofthe-refugee-crisis/. Acesso em: 12 set. 2017.

VEBLEN, Thorstein. A teoria da classe ociosa: um estudo econômico das instituições. São Paulo: Nova Cultural, 1987. cap. 2, p. 37.

WATKINS, Kevin; QUATTRI, Maria et al. The state of the world's children 2016: a fair chance for every child. London: Soapbox, 2016. Disponível em: http://www.crianca.mppr.mp.br/arquivos/File/ publi/unicef_sowc/sit_mund_inf_2016.pdf. Acesso em: 12 set. 2017. 
